\title{
Orthopaedic surgeons' perceptions on COVID-19 related changes in practice: an international survey
}

Nadhir Meraghni ( $\nabla$ nadhir.meraghni@gmail.com )

Centre Hospitalier Universitaire Mustapha Bacha

\section{Hichem Bouyoucef}

Centre hospitalier Sainte Catherine

Nacim soal

The Ouarsenis Medical Center

Redouane Si Larbi

The Ouarsenis Medical Center

\section{Riad Benkaidali}

Centre Hospitalier Universitaire Mustapha Bacha

\section{Zoubir Kara}

Centre Hospitalier Universitaire Mustapha Bacha

\section{Amine Hamza}

Centre hospitalier du Mans

\section{Short Report}

Keywords: COVID-19, orthopedic surgeon, pandemic

Posted Date: September 1st, 2020

DOI: https://doi.org/10.21203/rs.3.rs-26258/v3

License: (c) (1) This work is licensed under a Creative Commons Attribution 4.0 International License.

Read Full License 


\section{Abstract}

\section{Purpose}

The purpose of this study was to assess the orthopaedic surgeons' perceptions on COVID-19 related changes in their practice.

\section{Methods}

An online survey was shared with orthopaedic surgeons practicing in different countries.

\section{Results}

This study showed that orthopaedic surgery plan management was adapted to respond more effectively to the COVID-19 pandemic while maintaining the continuity of health care and ensuring protection of medical staff and patients. Among the introduced measures, elective surgery was postponed to free-up beds for suspected or COVID-19 positive patients requiring hospitalization. Additionally, the number of outpatient visits was considerably decreased and non-urgent visits were postponed to reduce the flow of patients in and out of hospitals and therefore minimize the risk of contamination. Interestingly, data revealed the willingness of orthopaedic surgeons to take care of COVID-19 positive patients and support their colleagues in intensive care units, if needed.

\section{Conclusions}

Though, orthopaedic surgeons are not in the frontline, they have an important role to play to face the increasing pressure due to the COVID-19 pandemic. In addition to the changes imposed in their current practice, they have a role in providing support to other colleagues in the fight against this global crisis.

\section{Introduction}

The COVID-19 pandemic is one of the largest global healthcare crises in nearly a century. The novel coronavirus crisis started in Wuhan, China in late 2019and has spread worldwide[1].On 11 March 2020, the World Health Organization (WHO) declared that the epidemic of COVID-19 had become a pandemic [2]. To face this global health emergency which has overwhelmed the health systems around the world, health institutions have had to readjust their functioning, to cope with COVID 19 while ensuring the continuity of care and protecting medical staff and patients[3]. At first glance, orthopaedic surgeons are not considered front-line staff in the fight against the COVID-19, comparing with our colleagues of other specialities: infectiologists, pneumologists and intensive care physicians. However, as part of the larger healthcare system, they also have an important role to play in reining in this pandemic[1, 4]. The purpose of this study was to assess the orthopaedic surgeons' perceptions on COVID-19 related changes in their practice.

\section{Materials And Methods}


We developed an online, anonymous web-based survey using non-probability snowball sampling technique

A 29-question anonymous survey (Table 1) was shared with orthopaedic surgeons practicing in different countries across social media orthopaedic groups and platforms. The questionnaire was designed to assess the orthopaedic surgeons' perceptions on COVID-19 related changes in their practice. We shared the online questionnaire and collected relevant data. Results were exported to Microsoft Excel version 2010 for analysis. The survey included different sections. The first one was about general information: country of practice, age, sector of activity and years of experience. Then, we asked about knowledge about the COVID-19: specific training, recommendations, risks and protection. The respondents were required to report their experience of care for COVID-19 positive patients and their motivation to work in COVID-19 units. Specific questions were asked about orthopaedic and trauma activity: number of surgeries (planned or emergency), number of outpatient visits and supply of orthopaedic equipment. They were also interrogated if they had reported symptoms or had suspected a COVID-19 infection and what were the measures taken about that. They were also required to report the level of personal protection at work, which equipment they used and which protection equipment is missing the most in their institution. Finally, the respondents were asked about their countries strategy and what do they think is the best solution to face the COVID-19 pandemic.

\section{Results}

534 orthopaedic surgeons representing 80 countries (Table 2) participated to the study.

The mean age of participants was $40 \pm 9$ years (min 29 years, max. 76 years old). $59 \%$ are working in public hospitals. $21 \%$ and $19 \%$ of participants have more than 10 and 20 years' experience in orthopaedic surgery, respectively. $60 \%$ of orthopaedic surgeons reported having extensive knowledge of COVID-19 and $53 \%$ have confirmed having received relevant training at their place of work. 425 surgeons asked $(79 \%)$ reported their awareness about measures of protection and risks for medical staff and patients.75 respondents (14\%) reported having operated on COVID-19 positive patients but $52 \%$ declared their willingness to operate suspected or COVID-19 positive patients with orthopaedic pathology. $62 \%$ of orthopaedic surgeons declared being ready to work and help in intensive care units if needed.

Concerning their specific activity, 55\% have cancelled elective surgeries while $16 \%$ reduced their activity by about $90 \%$.The number of emergency and trauma surgeries has decreased for the majority of physicians asked, by $90 \%$ for $18 \%$ and by $50 \%$ for $23 \%$ of them. $16 \%$ of surgeons declared having the same trauma activity as usual(Fig. 1).In the same way, more than $59 \%$ notified a clear decrease (more than $75 \%$ ) on the number of traffic accidents. $26 \%$ reduced the number of outpatient visits by $90 \%$ while 113 surgeons (21\%) have cancelled all outpatient visits. In the same way, more than $59 \%$ notified a clear decrease (superior than $75 \%$ ) on the number of traffic accidents. The supply of orthopaedic equipment for the orthopaedic departments was not affected according to $60 \%$ of respondents.338 doctors (63\%) have used telemedicine with their patients during the COVID-19 pandemic. 147 surgeons $(27 \%)$ 
experienced one or many symptoms suspecting a COVID-19 infection. The best option was to stay home and observe their symptoms for $51 \%$ of them. $62 \%$ of respondents reported self-isolating at home when they return back from work place. $74 \%$ declared feeling stressed and anxious about this global pandemic. The equipment used for personal protection are medical masks, respirator N 95 or FFP2 masks, face shields, gloves, gowns and protective glasses.77\% of respondents estimated that their countries were under-equipped to deal with the COVID-19 pandemic while 57\% were in agreement with their institutions strategies to face this crisis. To avoid COVID-19, orthopaedic surgeons asked recommend to people: regular hands washing, hydro-alcoholic sanitizer, social distancing, face masks, gloves and of course to stay home. Finally, $37 \%$ of the interviewed doctors believe that the best solution for COVID-19 would be to make a specific vaccine while $37 \%$ proposed respect of quarantine as a preventive method to face the Covid-19 pandemic.

\section{Discussion}

Orthopaedic practice has been markedly affected by the emergence of the COVID-19 outbreak. Changes to clinical practice have been largely guided by clinical urgency, patients and medical staff protection and conservation of health-care resources. Having said that, changes to inpatient and outpatient care have been accordingly tailored to reduce the risk of contamination in patients, medical staff and to allow hospitals to free up beds for treatment of patients with positive or suspected COVID-19 [4, 5]. All elective surgical procedures should be cancelled and deferred until an opportune time [6]. Trauma cases surgeries should continue to proceed. Intraoperatively, full personal protection including surgical shields and goggles should be used. Operative times should be reduced whenever feasible, and surgical team should be kept to the minimum, whenever possible $[4,5,7]$. The reported decrease in the number of road accidents is due to the lockdown policy imposed by several countries worldwide and remote work adopted by a large number of institutions and organizations. Further measures may also be implemented. Hospitals should be in lockdown with no visitors allowed, social distancing at work (between coworkers) and at home (between cohabiting health-care workers). Physicians have also been advised to prolong the duration between non-urgent follow-ups to reduce patient overcrowding in hospitals $[4,5,7]$. Although non-urgent clinics and surgical procedures have been postponed until the situation improves, we must ensure that appropriate quality of care given to our patients is maintained. The emergence of such a crisis provides a timely opportunity for us to reflect and evaluate the use of novel technologies in the workplace. This includes the adoption of telemedicine and telerehabilitation initiatives, allowing patients to be consulted and followed-up in the comfort of their own homes $[4,5,8-$ 10].

Apart from the information shared by healthcare institutions, healthcare professionals used various other sources of information such as television, social media and World Health Organization website (Table 3) [11].

This study demonstrated high level of awareness amongst orthopaedic surgeons about the risk of infection in healthcare professionals and patients as well as the preventive measures for stopping or 
minimizing spread of the disease. Given the increased risk for transmission COVID-19 virus in hospitals in general and operating theaters in particular, special personal protective measures must be provided. As surgeons, utmost care must be given to patients in the preoperative, intraoperative, and postoperative settings to minimize the risks of contamination. The risks and benefits of surgical management should be rationalized for each patient $[4,11,12]$.COVID-19 has shown more infectivity and a higher fatality rate than the H1N1 epidemic [2, 11]. In addition, important clinical features of COVID-19 are currently unknown. These two elements may explain the number of interviewees (48\%) who expressed reluctance to treat or operate non-urgent conditions in COVID-19 positive patients. Notably, the most common reason for their unwillingness to treat COVID-19 positive patients is due to their concern of getting the infection and transmitting the virus to their family members. With a better understanding of COVID-19 characteristics, we would expect a gradual increase in the number of medical staff who will be willing to treat infected patients[2, 11].The COVID-19 crisis has resulted in people working outside their specialty, providing support toinfectiologist, pneumologist and intensive care physicians $[1,5]$. We know that virus is likely to cause minor symptoms in majority (more than $80 \%$ ) of infected people. Many healthcare workers are likely to fall into this category [1].Orthopaedic surgeons have a reputation built on their versatility and strength. Emotional support is necessary for ourselves, colleagues, patients and families $[1,13,14]$.Most interviewed practitioners estimated appropriate protective measures have been provided at work (table 4). Provision of personal protective equipment to healthcare professionals has been a huge challenge in many countries $[1,7,15]$.

Personal protective equipment included medical masks, respirator N 95 or FFP2 masks, face shields, gloves, gowns, and protective glasses $[11,16,17]$. Given the extent of the pandemic, a shortage of a widely used equipment has been reported with FFP2 masks arrive in the top of the list -reported by $58 \%$ of the interviewed participants- (table 5).Institutions and governments have put in place different strategies to face this shortage, notably, support increasing production capacity and accelerating approval of protective equipment during this crisis $[17,18]$. To help prevent spread of COVID-19, orthopaedic surgeons recommendations were frequent hand washing for a minimum 20 seconds, use hydro-alcoholic sanitizer, social distancing, use of face masks, gloves and of course confinement while waiting to discover a specific treatment and to make a specific vaccine.

We recognize certain limitations in our study. The data collected are subjective and represent perceptions of

orthopaedic surgeons asked. Few countries have enough participants to make meaningful inferences about these responses relevant to each country. Another limitation is that the non-response rate could not be calculated and distribution of responses was skewed. The severity of the outbreak was not the same in all countries, so the measures taken by governments and health institutions were different [12]. Finally, the experience of the person who fills out the questionnaire may affect the results.

\section{Conclusion}


The COVID-19 pandemic has posed an unprecedented challenge for healthcare systems and clinicians around the world. This pandemic has confronted the orthopaedic community with challenges never encountered by our profession. During this unprecedented time, in addition to the changes imposed in our current practice, we have to get out of our comfort zones to work as a team with all of our colleagues to face the COVID-19.

\section{Declarations}

\section{Conflict of interest:}

On behalf of all authors, the corresponding author states that there is no conflict of interest.

\section{Funding}

The authors received no external funding for this research.

\section{References}

1. Ashford RU, Nichols JS, Mangwani J (2020) Annotation: The COVID-19 pandemic and clinical orthopaedic and trauma surgery. J Clin Orthop Trauma S0976566220301168 . https://doi.org/10.1016/j.jcot.2020.04.002

2. Shi Y, Wang J, Yang Y, Wang Z, Wang G, Hashimoto K, et al. (2020) Knowledge and attitudes of medical staff in Chinese psychiatric hospitals regarding COVID-19. Brain Behav Immun - Health 4:100064 . https://doi.org/10.1016/j.bbih.2020.100064

3. Viswanath A, Monga P (2020) Working through the COVID-19 outbreak: Rapid review and recommendations for MSK and allied heath personnel. J Clin Orthop Trauma S0976566220300977. https://doi.org/10.1016/j.jcot.2020.03.014

4. Chang Liang Z, Wang W, Murphy D, Po Hui JH (2020) Novel Coronavirus and Orthopaedic Surgery: Early Experiences from Singapore. JBJS Latest Articles: . https://doi.org/10.2106/JBJS.20.00236

5. Giacomo P, Damiano S, Elena D, Giulia B, Vincenzo S (2020) CoViD-19 and Ortho and Trauma Surgery: the Italian Experience. Injury S0020138320303430. https://doi.org/10.1016/j.injury.2020.04.012

6. Massey PA, McClary K, Zhang AS, Savoie FH, Barton RS (2020) Orthopaedic Surgical Selection and Inpatient Paradigms During the Coronavirus COVID-19 Pandemic. JAAOS - J Am Acad Orthop Surg Publish Ahead of Print: . https://doi.org/10.5435/JAAOS-D-20-00360

7. Ahmed S, Leong Glenn TW, Chong Y-L (2020) Surgical Response to COVID-19 Pandemic: A Singapore Perspective. J Am Coll Surg S1072751520303082 . https://doi.org/10.1016/j.jamcollsurg.2020.04.003 
8. Vaccaro AR, Getz CL, Cohen BE, Cole BJ, Donnally CJI (2020) Practice Management During the COVID-19 Pandemic. JAAOS - J Am Acad Orthop Surg Publish Ahead of Print: . https://doi.org/10.5435/JAAOS-D-20-00379

9. Loeb AE, Rao SS, Ficke JR, Morris CD, Riley LHI, Levin AS (2020) Departmental Experience and Lessons Learned With Accelerated Introduction of Telemedicine During the COVID-19 Crisis. JAAOS J Am Acad Orthop Surg Publish Ahead of Print: . https://doi.org/10.5435/JAAOS-D-20-00380

10. Parisien RL, Shin M, Constant M, Saltzman BM, Li X, Levine WN, et al. (2020) Telehealth Utilization in Response to the Novel Coronavirus (COVID-19) Pandemic in Orthopaedic Surgery. JAAOS - J Am Acad Orthop Surg Publish Ahead of Print: . https://doi.org/10.5435/JAAOS-D-20-00339

11. Awad ME, Rumley JCL, Vazquez JA, Devine JG (2020) Peri-operative Considerations in Urgent Surgical Care of Suspected and Confirmed COVID-19 Orthopedic Patients: Operating rooms protocols and recommendations in the Current COVID-19 Pandemic. JAAOS - J Am Acad Orthop Surg Publish Ahead of Print: . https://doi.org/10.5435/JAAOS-D-20-00227

12. Tan Z, Phoon PHY, Zeng LA, Fu J, Lim XT, Tan TE, et al. (2020) Response and Operating Room Preparation for the COVID-19 Outbreak: A Perspective From the National Heart Centre in Singapore. J Cardiothorac Vasc Anesth S1053077020303001 . https://doi.org/10.1053/j.jvca.2020.03.050

13. Li Z, Ge J, Yang M, Feng J, Qiao M, Jiang R, et al. (2020) Vicarious traumatization in the general public, members, and non-members of medical teams aiding in COVID-19 control. Brain Behav Immun. https://doi.org/10.1016/j.bbi.2020.03.007

14. Lu W, Wang H, Lin Y, Li L (2020) Psychological status of medical workforce during the COVID-19 pandemic: A cross-sectional study. Psychiatry Res 288:112936 . https://doi.org/10.1016/j.psychres.2020.112936

15. Lancaster EM, Sosa JA, Sammann A, Pierce L, Shen W, Conte M, et al. (2020) Rapid Response of an Academic Surgical Department to the COVID-19 Pandemic: Implications for Patients, Surgeons, and the Community. J Am Coll Surg S1072751520303124 . https://doi.org/10.1016/j.jamcollsurg.2020.04.007

16. Gan WH, Lim JW, Koh D (2020) Preventing Intra-hospital Infection and Transmission of Coronavirus Disease 2019 in Health-care Workers. Saf Health Work. https://doi.org/10.1016/j.shaw.2020.03.001

17. Ellis R, Hay-David AGC, Brennan PA (2020) Operating during the COVID-19 pandemic: How to reduce medical error. Br J Oral Maxillofac Surg S0266435620301467. https://doi.org/10.1016/j.bjoms.2020.04.002

18. Dunham AM, Rieder TN, Humbyrd CJ (2020) A Bioethical Perspective for Navigating Moral Dilemmas Amidst the COVID-19 Pandemic. JAAOS - J Am Acad Orthop Surg Publish Ahead of Print: . https://doi.org/10.5435/JAAOS-D-20-00371

\section{Tables}

Table 1 : Survey questions 
Q1 - Country of practice

Q2 - Age

Q3 - Sector of practice

oPublic oPrivate

Q4 - How many years have you practiced orthopaedic surgery

o 0 - 5 years $05-10$ years $010-20$ years $0>20$ years

Q5 - Have you received a specific training or recommendations about COVID-19 from your institution

oYes oNo

Q6- Do you feel well informed on the latest COVID-19 guidelines

oVery well informed

oWell informed

oSomewhat informed

oPoorly informed

Q7 - What is your principal source of knowledge about COVID-19

oTelevision

oSocial media

oWHO $(\mathrm{OMS})=$ world health organization

oYour institution (hospital, clinic)

Q8 - Are you aware of the measures to protect yourself and patients during the COVID-19 pandemic 
Q9 - Are you aware of all the risks of COVID-19 pandemic for patients and medical staffs?
oYes oNo
oNot sure

Q10 - Have you already operated on patients positive with COVID-19

oYes oNo

Q11 - Are you willing to operate COVID-19 positive patients with an orthopaedic pathology
oYes oNo
oNot sure

Q12 - Are you willing to work and help in Intensive care units if necessary

oYes oNo oNot sure

Q13 - Actually, with the COVID-19 pandemic, the number of planned surgeries you are practicing is:

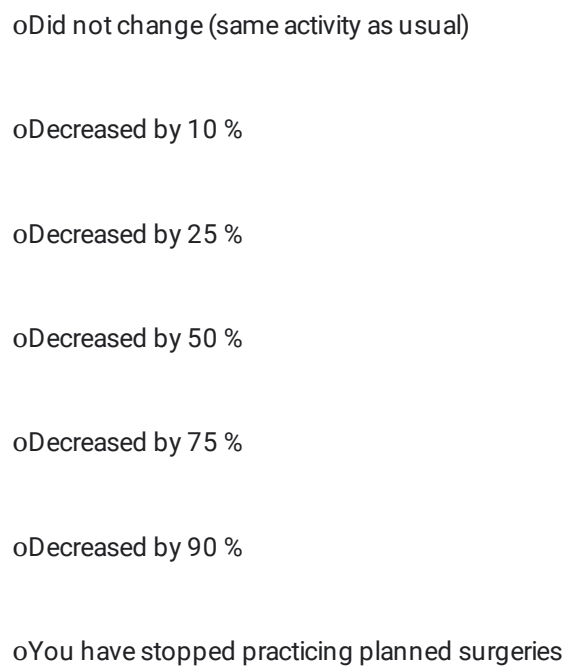


oDid not change (same activity as usual)

oDecreased by $10 \%$

oDecreased by $25 \%$

oDecreased by $50 \%$

oDecreased by $75 \%$

oDecreased by $90 \%$

oYou have stopped practicing emergency surgeries

Q15 - Actually, with the Covid 19 pandemic, the number of outpatient visits:

o Did not change (same activity as usual)

o Decreased by $10 \%$

o Decreased by $25 \%$

o Decreased by $50 \%$

o Decreased by $75 \%$

o Decreased by $90 \%$

o You have stopped consultation

Q16 - Actually, with the COVID-19 pandemic, the number of traffic accidents:

o Did not change

o Decreased by $10 \%$

o Decreased by $25 \%$

o Decreased by $50 \%$

o Decreased by $75 \%$

o Decreased by $90 \%$

o Has increased 
Q17 - Has the crisis affected the number and quantity of orthopaedic equipment ordered by your institution?

oYes oNo

Q18 - Actually, with the COVID-19 pandemic, have you used telemedicine for your patients

oYes oNo

Q19 - During this COVID-19 pandemic, have you experienced any or more of the following symptoms: Fever, cough, runny nose, headaches, sore throat, tiredness, asthenia

oYes oNo

Q20 - If Yes or you have a suspicion of a COVID-19 infection, what would you do

oStay at home and observe yourself

oCall a specific COVID-19 phone number

oGo to the Institution where you work

oGo to the nearest hospital

oOther

Q21 - Do you isolate yourself at home when you retum back from your workplace

oYes oNo

oOther: .....................

Q22 - Do you feel stressed and anxious about this COVID-19 pandemic

oYes oNo

Page $11 / 16$ 
Q23 - How do you estimate your personal protection against COVID-19 during your medical practice

Please choose from $1=$ not protected to $5=$ well protected

$\begin{array}{lllll}01 & 02 & 03 & 04 & 05\end{array}$

Q24 - Which equipment do you use for your personal protection against COVID-19

- Medical mask

- Respirator N 95 or FFP2 mask

- Face Shield

- Gloves

- Gown

- Protective glasses

Q25 - Which personal protection equipment stock your institution is missing the most

- Medical mask

- Respirator N 95 or FFP2 mask

- Face Shield

- Gloves

- Gown

- Protective glasses

Q26 - What advice could you give to people to avoid COVID-19

- Regular washing of hands

- Hydro-Alcoholic sanitizer

- Social distancing

- Face mask 
- Gloves

- Stay home

Q27 - Do you think that your country is well equipped to deal with this

COVID-19 pandemic

oYes oNo oNot sure

Q28 - Do you agree with your institution strategy to face the COVID-19 pandemic

oYes oNo

Q29 - In your opinion, which is the best solution to face the Covid 19 pandemic

- Quarantine

- Herd immunity

- Find a specific treatment

- Find a specific vaccine

- Other

Table 2: List of countries 


\begin{tabular}{|c|c|}
\hline Country & Responses \\
\hline Albania & 1 \\
\hline Algeria & 185 \\
\hline Andorra & 1 \\
\hline Argentina & 2 \\
\hline Australia & 2 \\
\hline Austria & 2 \\
\hline Bangladesh & 3 \\
\hline Barbados & 1 \\
\hline Belgium & 27 \\
\hline Brazil & 18 \\
\hline Burkina Faso & 3 \\
\hline Cameroon & 1 \\
\hline Canada & 3 \\
\hline Central AfricanRepublic & 1 \\
\hline Colombia & 3 \\
\hline Congo (RDC) & 1 \\
\hline Cote d'Ivoire & 3 \\
\hline Croatia & 4 \\
\hline Egypt & 6 \\
\hline El Salvador & 1 \\
\hline Finland & 6 \\
\hline Georgia & 1 \\
\hline Germany & 3 \\
\hline Hong Kong & 1 \\
\hline Hungary & 1 \\
\hline India & 57 \\
\hline Indonesia & 4 \\
\hline Iran & 4 \\
\hline Iraq & 1 \\
\hline Ireland & 1 \\
\hline Italy & 7 \\
\hline Japan & 4 \\
\hline Kenya & 3 \\
\hline Latvia & 1 \\
\hline Lebanon & 1 \\
\hline Libya & 2 \\
\hline Luxembourg & 4 \\
\hline Macedonia & 1 \\
\hline Madagascar & 2 \\
\hline Malaysia & 1 \\
\hline Mali & 1 \\
\hline Mauritania & 1 \\
\hline Mexico & 1 \\
\hline Moldova & 2 \\
\hline Monaco & 1 \\
\hline Morocco & 9 \\
\hline Namibia & 1 \\
\hline Nepal & 9 \\
\hline New Zealand & 1 \\
\hline Nigeria & 5 \\
\hline Oman & 3 \\
\hline Pakistan & 6 \\
\hline ParacelIslands & 1 \\
\hline Paraguay & 10 \\
\hline Philippines & 4 \\
\hline Poland & 1 \\
\hline
\end{tabular}

Page 14/16 


\begin{tabular}{|l|l|}
\hline Portugal & 2 \\
\hline Qatar & 1 \\
\hline Romania & 14 \\
\hline Russia & 5 \\
\hline SaudiArabia & 3 \\
\hline Senegal & 4 \\
\hline Singapore & 2 \\
\hline South Africa & 2 \\
\hline Spain & 1 \\
\hline Sudan & 1 \\
\hline Sweden & 6 \\
\hline Switzerland & 11 \\
\hline Syria & 1 \\
\hline Taiwan & 2 \\
\hline Togo & 2 \\
\hline Tunisia & 12 \\
\hline Turkey & 2 \\
\hline Uganda & 2 \\
\hline Ukraine & 1 \\
\hline United Kingdom & 17 \\
\hline United States & 11 \\
\hline Uzbekistan & 1 \\
\hline Vietnam & 1 \\
\hline Yemen & 1 \\
\hline Total & 534 \\
\hline
\end{tabular}

\begin{tabular}{|l|r|r|}
\hline & Sources of knowledge about COVID-19 & \\
\hline Your institution (hospital, clinic) & 212 & $39,41 \%$ \\
\hline Social media & 49 & $9,11 \%$ \\
\hline WHO (OMS) = world health organization & 124 & $23,05 \%$ \\
\hline Television & 153 & $28,44 \%$ \\
\hline Total & $\mathbf{5 3 8}$ & $\mathbf{1 0 0 , 0 0 \%}$ \\
\hline
\end{tabular}

Table 3. Sources of knowledge about COVID-19

\begin{tabular}{|l|r|r|r|}
\hline & \multicolumn{3}{|c|}{$\begin{array}{l}\text { How do you estimate your personal protection against COVID-19 during your medical practice [Please } \\
\text { choose from 1= not protected to 5 = well protected] }\end{array}$} \\
\hline $\mathbf{1}$ & 80 & $14,87 \%$ \\
\hline $\mathbf{2}$ & 118 & $21,93 \%$ \\
\hline $\mathbf{3}$ & 209 & $38,85 \%$ \\
\hline $\mathbf{4}$ & 101 & $18,77 \%$ \\
\hline $\mathbf{5}$ & 30 & $5,58 \%$ \\
\hline Total & $\mathbf{5 3 8}$ & $\mathbf{1 0 0 , 0 0 \%}$ \\
\hline
\end{tabular}

Table 4. Degree of personal protection 


\begin{tabular}{|l|r|r|r|}
\hline & \multicolumn{3}{|l|}{$\begin{array}{l}\text { Which personal protection equipment stock your institution is missing the } \\
\text { most }\end{array}$} \\
\hline Face Shield & 66 & $12,27 \%$ \\
\hline Gloves & 7 & $1,30 \%$ \\
\hline Gown & 33 & $6,13 \%$ \\
\hline Medicalmask & 79 & $14,68 \%$ \\
\hline Protective glasses & 42 & $7,81 \%$ \\
\hline $\begin{array}{l}\text { Respirator N 95 or FFP2 } \\
\text { mask }\end{array}$ & 311 & $57,81 \%$ \\
\hline Total & 538 & $100 \%$ \\
\hline
\end{tabular}

Table 5. Personal protection equipment

\section{Figures}

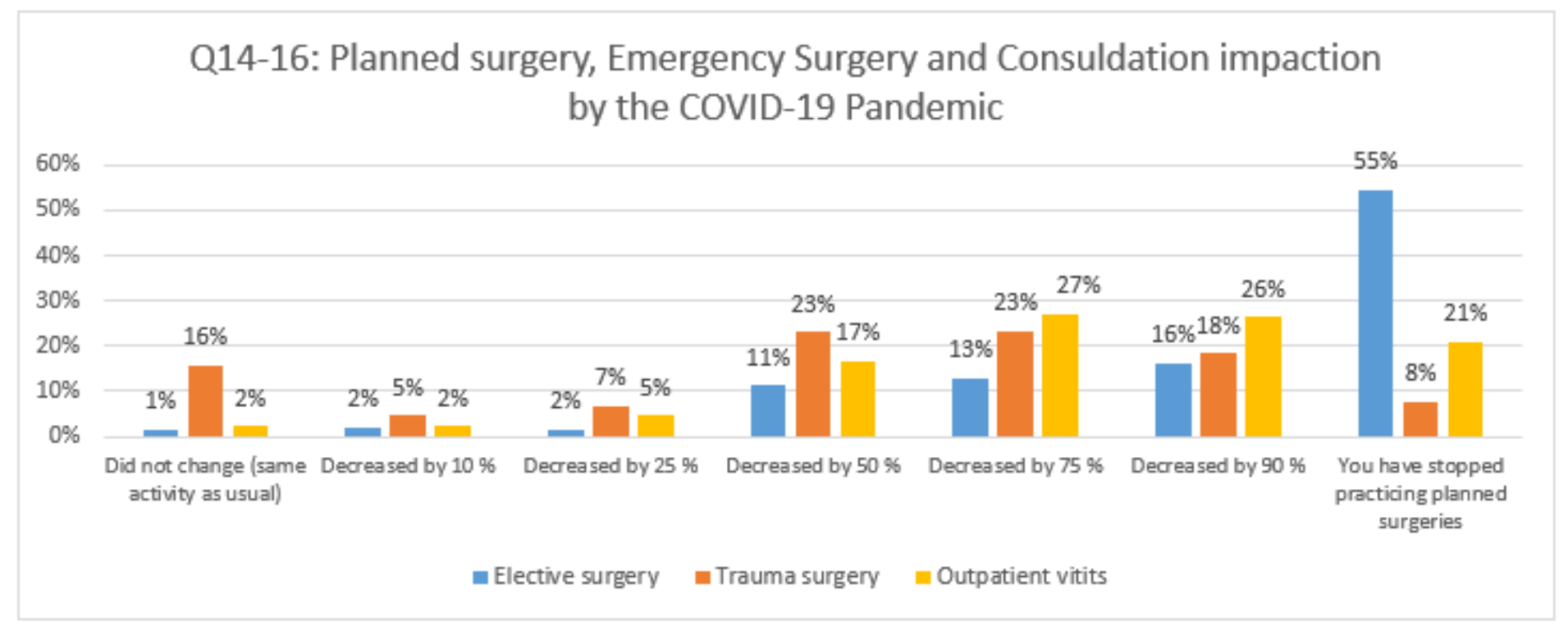

\section{Figure 1}

Impact on the elective surgery, trauma surgery and outpatient visits 